\title{
DO GORILA AMESTRADO DE TAYLOR AO MACACO DE NICOLELIS
}

\author{
FROM TAYLOR'S TAMED GORILLA TO NICOLELIS' MONKEY
}

Laymert Garcia dos Santos ${ }^{1}$

Rafael Alves da Silva ${ }^{2}$

Pedro Peixoto Ferreira ${ }^{3}$

Resumo Partindo de uma análise de Gramsci das transformações pelas quais passava o trabalhador humano no capitalismo do início do século XX, busca-se neste texto indicar aspectos de como tais processos de transformação vêm se dando no capitalismo do início do século XXI. Para isso, abordamos a transição da problemática muscular e energética da substituição do trabalhador humano pela máquina para a problemática cognitiva e informacional do controle nos acoplamentos homem-máquina. Do gorila amestrado de Taylor ao macaco de Nicolelis, mudaram as formas de subsunção do trabalhador ao capital, mas não a própria subsunção.

Palavras-chave trabalho e tecnologia; industrialismo; adaptação psicofísica; neurociência; humano-máquina.
Abstract With Gramsci's analysis of the transformations the human worker underwent in capitalism in the early 20th century as a starting point, this article seeks to point to aspects of how such transformation processes are taking place in capitalism in the early 21 st century. To achieve this, we approach the transition from muscular and energetic problem of substituting human for machine labor to the cognitive and informational issue of control in the man-machine couplings. From Taylor's tamed gorilla to Nicolelis' monkey, the forms of subsumption of the worker to capital changed, but not the actual subsumption.

Keywords labor and technology; industrialism; psychophysical adaptation; neuroscience; humanmachine. 
Há séculos a cultura ocidental desenvolve o trabalho.

Há séculos a cultura ocidental desenvolve os meios de produção.

Há séculos a cultura ocidental desenvolve meios para controlar a saúde.

O que pode ocorrer se a saúde for pensada em função do trabalho e não da vida, de um trabalho entendido unicamente como produtor de valores de troca, como trabalho abstrato dentro do sistema capitalista?

A discussão sobre a adaptação do homem para o trabalho não é nenhuma novidade. Já nos anos 1930, ao analisar as transformações pelas quais passava a produção e a vida social com a implementação das práticas tayloristas/fordistas, Gramsci apontou para a formação de um novo homem e de uma nova sociedade:

A história do industrialismo sempre foi (e hoje o é de forma mais acentuada e rigorosa) uma luta contínua contra o elemento 'animalidade' do homem, um processo ininterrupto, muitas vezes doloroso e sangrento, de sujeição dos instintos (naturais, isto é, animalescos e primitivos) a sempre novos, complexos e rígidos hábitos e normas de ordem, exatidão, precisão, que tornem possível as formas sempre mais complexas de vida coletiva, que são a consequência necessária do desenvolvimento do industrialismo. Esta luta é imposta do exterior e até agora os resultados obtidos, embora de grande valor prático imediato, são em grande parte puramente mecânicos, não se transformaram numa 'segunda natureza'. Mas, todo novo modo de vida, no período em que se impõe a luta contra o velho, não foi sempre durante certo tempo o resultado de uma compressão mecânica? Inclusive os instintos que hoje devem ser superados como ainda bastante 'animalescos' constituíram, na realidade, um progresso notável em relação aos anteriores, ainda mais primitivos: quem poderia enumerar o 'custo', em vidas humanas e em dolorosas sujeições dos instintos, da passagem do nomadismo à vida sedentária e agrícola? (...)

Até agora, todas as mudanças do modo de ser e viver se verificaram através da coerção brutal, através do domínio de um grupo social sobre todas as forças produtivas da sociedade: a seleção ou 'educação' do homem apto para os novos tipos de civilização, para as novas formas de produção e de trabalho, foi realizada com o emprego de brutalidades inauditas, lançando no inferno das subclasses os débeis e os refratários, ou eliminando-os simplesmente (Gramsci, 1980, p. 391-393).

Gramsci contempla as transformações de seu tempo como uma etapa dentro de um processo que deve continuar. Aponta a adaptação dos trabalhadores, necessária para atender às mudanças na produção - adaptação esta que não se limita às questões físicas ou psicológicas, mas também envolve os costumes e todo um modo de vida que deve se expandir pela sociedade, eliminando aqueles que não se adaptarem. E continua: 
[O fenômeno americano] é também o maior esforço coletivo realizado até agora para criar, com rapidez incrível e com uma consciência do fim jamais vista na História, um tipo novo de trabalhador e de homem. (...) Efetivamente [com a frase sobre o 'gorila amestrado'], Taylor exprime com cinismo brutal o objetivo da sociedade americana; desenvolver ao máximo, no trabalhador, as atitudes maquinais e automáticas, romper o velho nexo psicofísico do trabalho profissional qualificado, que exigia uma determinada participação ativa da inteligência, da fantasia, da iniciativa do trabalhador, e reduzir as operações produtivas apenas ao aspecto físico maquinal. Mas, na realidade, não se trata de novidades originais, trata-se de um longo processo que começou com o próprio nascimento do industrialismo, fase que apenas é mais intensa que as precedentes e manifesta-se sob formas mais brutais, mas que também será superada com a criação de um novo nexo psicofísico de um tipo diferente dos precedentes e, indubitavelmente, superior. Verificar-se-á, inevitavelmente, uma seleção forçada, parte da velha classe trabalhadora será impiedosamente eliminada do mundo do trabalho e talvez do mundo tout court (Gramsci, 1980, p. 396-397, grifos do autor).

Se o quadro descrito por Gramsci na década de 1930 era a 'fase mais intensa' desse processo de adaptação do homem ao trabalho dentro do industrialismo, o que dizer da fase atual?

\section{Da substituição ao acoplamento}

Sempre que se pensa sobre como as novas tecnologias interferem no mundo do trabalho, o tema da substituição do trabalhador pela máquina aparece com veemência. Sabe-se que o ponto de inflexão no processo histórico de mecanização do trabalho humano (reprodução mecânica de capacidades humanas) foi quando os inventores deixaram de tentar simular, na forma de androides, toda a complexidade de um só indivíduo humano, e passaram a buscar reproduzir, na forma de mecanismos não-antropomórficos, movimentos simples de uma multidão. ${ }^{4}$ De fato, se considerarmos o atual estágio de desenvolvimento das forças produtivas no final da primeira década do século XXI, constataremos que, se por um lado as máquinas ainda não são capazes de substituir um ser humano em sua complexidade, por outro elas já substituem facilmente ações simples de uma multidão de seres humanos. Assim, poderíamos dizer que o primeiro passo para se tornar substituível por uma máquina é, como o gorila amestrado de Taylor, agir como uma, eliminando ao máximo qualquer singularidade de sua ação.

Mas seria o problema da substituição do trabalhador pela máquina realmente o mais importante hoje em dia? Afinal, quando uma empresa de call center sugere que suas funcionárias utilizem fralda para não haver gasto de 
tempo com ida ao banheiro, ${ }^{5}$ ou quando os funcionários de uma empresa de telemarketing "ficam impossibilitados, até mesmo, de irem ao banheiro atender às suas necessidades fisiológicas" (Santos, 2007, p. 161), talvez o empregado com necessidades fisiológicas já não sirva mais há muito tempo. Estamos efetivamente numa fase bem mais intensa do que aquela apontada por Gramsci, e o desenvolvimento e a disseminação das tecnologias da informação ao longo da segunda metade do século XX estão intimamente ligados a essa intensificação.

Nesse novo cenário, a exploração do trabalho vivo continua sendo a base do sistema, colocando em movimento os meios de produção e, assim, gerando valor econômico para o capitalista. No entanto, essa exploração vem se dando cada vez menos nas atividades repetitivas da produção (agricultura e indústria) - em que as máquinas (trabalho morto que não gera valor econômico) vêm sistematicamente substituindo milhões de trabalhadores desde o século XVIII - e mais em atividades complexas de circulação e consumo (serviços, indústrias culturais, indústrias criativas etc.) - em que trabalhadores precarizados, mas ainda insubstituíveis por máquinas, se digladiam numa espécie de competição tecnocientífica pelo melhor valor no mercado.

Na competição entre si e com as máquinas, remédios estimulantes são utilizados largamente pelas pessoas para melhorar o desempenho, desde o 'rebite' do caminhoneiro para ficar acordado até a cocaína aspirada pelo executivo do mercado financeiro, passando pelo uso de drogas como 'extensão natural da educação' (Laurence, 2009). Alguns medicamentos pesquisados pela indústria farmacêutica, como o modafinil ou a ritalina, vêm sendo utilizados para driblar o sono, e outros como a ampaquina estão sendo estudados para estimular a memória. Vale frisar que não se trata de um estímulo do tipo 'biotônico Fontoura'. No caso da ampaquina, por exemplo, a preocupação dos pesquisadores é que não se consiga esquecer mais nada, e para o modafinil "há quem diga ser possível ficar acordado por 60 horas sem nem piscar os olhos" (Clemente e Veiga, 2005, p. 77). Steven Hyman, professor de neurobiologia da Faculdade de Medicina de Harvard, manifestou sua preocupação diante de tais pesquisas:

Como ficam aquelas pessoas com menos recursos, que não poderão comprar essas drogas? Vamos criar mais um gap entre ricos e pobres. (...) Se várias pessoas começarem a tomar drogas para não dormir e funcionar 24 horas por dia, todo mundo vai se sentir coagido a fazer o mesmo. Caso contrário, não poderá competir no ambiente de trabalho (Hyman, apud Clemente e Veiga, 2005, p. 77-78).

Uma das grandes estrelas do ExpoManagement de 2007 foi Ray Kurzweil, inventor, empresário e propagador da Singularidade - conceito que defende que em poucas décadas, com os avanços exponenciais da nano- 
tecnologia, da robótica e da biotecnologia, a humanidade irá deparar-se com o advento de uma superinteligência (Bercito, 2007). O inventor é conhecido por prever que em breve teremos à disposição microcomputadores do tamanho de uma ervilha que poderemos implantar no cérebro para, entre outras coisas, otimizar nossas funções cognitivas. Qualquer estranhamento no fato de um pesquisador da inteligência artificial ser palestrante para profissionais da área de 'recursos humanos' deveria se dissipar à luz das implicações, nos problemas da qualificação profissional e da competitividade no mercado de trabalho, dos cenários por ele apresentados.

Em um texto curto, mas preciso, Lev Manovich (1995) discutiu as transformações no trabalho humano por ocasião da transferência da ênfase industrial nas atividades físicas para a ênfase pós-industrial nas atividades mentais: trabalho de processamento de informação, de controle, de concepção. Segundo Manovich, a questão não é se o trabalho físico foi substituído pelo trabalho mental (isto difere de indústria para indústria e entre os países), mas sim como a obsessão pela racionalização da atividade mecânica no trabalho (e.g. taylorismo) foi substituída, a partir da Segunda Guerra Mundial, pela racionalização dos processos mentais pelas ciências cognitivas e pela inteligência artificial. Enquanto a primeira obsessão levava à substituição do trabalhador humano pela máquina, a segunda vem levando a um acoplamento cada vez mais íntimo e completo entre eles.

\section{Otimização e registro}

Em um experimento famoso (Nicolelis, 2001; Nicolelis e Chapin, 2002; Lebedev et al., 2005; Lobo, 2006), o neurocientista brasileiro Miguel Nicolelis fixou eletrodos - mais precisamente, uma Brain-Machine-Interface (BMI) - no cérebro de um macaco preso diante de uma TV. Com uma espécie de joystick, o macaco comandou durante algum tempo formas que se moviam na TV e que, quando coordenadas adequadamente, liberavam uma certa dose de suco para o animal. Oculto do macaco estava um braço mecânico, que ele comandava com seu joystick e que tinha sua posição indicada por uma das formas que ele via na TV.

À medida que o macaco dobrava o joystick repetidamente para todos os lados, a BMI registrava os padrões de atividade de seu cérebro. Cruzando as informações registradas no cérebro com aquelas registradas no joystick (cruzando, poderíamos dizer, o cérebro com a mão), a BMI pôde elaborar um modelo preditivo capaz de traduzir um no outro. Quando o modelo alcançou um grau de predição aceitável, Nicolelis transferiu o controle para o cérebro e desligou o joystick. O macaco logo deixou de dobrar o joystick para mover as formas na TV - ou melhor, para mover o braço mecânico cuja 
posição era indicada pelas formas na TV. Bastava 'pensar' em movê-las (ou seja, produzir em seu cérebro os mesmos padrões de atividade de quando ele movia o joystick com a mão em determinada direção) e o sistema se encarregava de transferir a ordem diretamente ao braço mecânico e este às formas. Não custa enfatizar que não foi o macaco que aprendeu a mover objetos sem mexer um músculo, mas sim a BMI que aprendeu a extrair os movimentos do braço do macaco diretamente de sua atividade cerebral, sem depender dos movimentos do próprio braço.

A mídia tem anunciado os avanços ciborguianos de Nicolelis com otimismo e apoio (e.g. Lobo, 2006). Seja louvando as aplicações médicas na área da protética inteligente (envolvendo inclusive sensibilidade e telecomando; Nicolelis, 2001), seja sonhando com dispositivos domésticos comandados pelo pensamento (cortar a grama sem sair do sofá etc.), predomina um discurso celebratório. Evidentemente, o cientista não precisa objetivar melhorias nos processos de trabalho, substituição de mais trabalho vivo por máquinas. Mas, assim como acontece de os remédios destinados inicialmente a quem tem algum desvio da curva considerada 'saudável' passarem a ser utilizados para 'melhorar' o desempenho de pessoas consideradas 'normais' dentro da competição do mercado, o que impediria que descobertas oriundas das pesquisas de Nicolelis viessem a ser aplicadas na 'otimização' da atividade cerebral?

O leitor atento e não conservador poderá perguntar: 'Qual o problema em 'otimizar' a atividade cerebral?' E aqui está toda a questão. Particularmente, não temos uma visão conservadora quanto à tecnologia, mas consideramos necessário chamar a atenção para os processos, ou os sistemas e discursos, dentro e por meio dos quais as opções tecnológicas estão sendo feitas. O que importa na discussão aqui é a intenção de decifrar a mente. Assim como os corpos foram medidos e escalonados, os experimentos atuais com as funções cerebrais visam entender o funcionamento da mente humana - nas palavras de Nicolelis, 'entender a alma'. Mas o que acontece quando o 'pensamento' - ou, se não quisermos recorrer à metáfora problemática de Nicolelis, o 'impulso motor acionado pela percepção' - se torna, em sua própria manifestação cerebral desvinculada de qualquer ação muscular, um registro legível por uma máquina?

Tudo gira em torno da operação de registro. É o registro que permite a mensuração, o arquivamento, a comparação e, no caso que nos interessa, a produção de valor econômico expropriável. A relação do registro com o registrado é o campo de batalha - o registro sendo a arma e o registrado o alvo. Mas o que está sendo registrado no experimento de Nicolelis?

Por um lado, não importa o que o macaco 'pensa' sobre as formas que vê na TV, sobre o jogo, sobre o suco etc. No limite, se entendermos bergsonianamente por pensamento aquela parte da atividade cerebral que reflete 
uma sensação (input) sem efetuar uma ação (output), 6 então notaremos que o registro na verdade não tem nada a ver com o pensamento, pois ele se limita ao cruzamento de padrões cerebrais com padrões motores.

Por outro lado, nota-se que o macaco como indivíduo coeso e coerente não importa, apenas aquela parte dele acoplada à máquina e dividida por ela. O indivíduo macaco permanece em grande parte excluído do registro, bebendo seu suco de acordo com seu desempenho no jogo. Mas o divíduo 'cérebro-braço', que em última análise nem precisa ser um macaco (sendo o objetivo justamente acoplar seres humanos às máquinas), está totalmente aberto ao registro e, consequentemente, à mensuração e ao controle.

Com efeito, ao assistir à gravação em vídeo de um dos experimentos de Nicolelis, somos levados a uma exaltação quando a macaca, sugestivamente chamada 'Aurora', larga o joystick. Admiramos o animal que 'aprendeu' a manipular o braço mecânico apenas com a força mental. A reflexão a respeito do experimento, porém, nos mostra que 'quem' aprendeu a realizar algo foi a máquina, somente ela ganhou uma atribuição nova, foi ela que 'aprendeu' a decodificar a atividade cerebral da macaca.

\section{Pesquisar, decifrar, controlar}

O primeiro passo para controlar é decifrar. Entender, traduzir, padronizar, controlar. Um sistema de gestão da qualidade baseado, por exemplo, na norma ISO 9000 primeiro precisa entender o trabalho do operador, depois transcrevê-lo em procedimentos documentados, para que todos sigam as mesmas condutas, para que tudo possa ser medido. Esse também é o primeiro passo para que a tarefa desse operador seja dividida em várias partes e distribuída aos demais, ou transcrita em um software ou robô de modo a eliminar esse posto de trabalho.

Não podemos acusar o estudo de Nicolelis de pretender o controle sobre a mente, mas também não podemos ignorar que as pesquisas contemporâneas em biotecnologia e neurociência se enquadram na lógica da racionalidade científica ocidental de entender a natureza pretendendo controlá-la. Estando tal racionalidade científica ocidental por sua vez enquadrada num sistema capitalista de produção, logicamente os avanços no conhecimento da natureza/controle da natureza privilegiarão sempre a valorização do valor em detrimento da realização de qualquer potencial humano.

É fácil verificar que, mesmo para Marx, o desenvolvimento das forças produtivas era desejável. Evidentemente, era necessário produzir para melhorar as condições de vida, era necessário liberar o homem do trabalho árduo e insalubre. Mas, na medida em que todo avanço é informado pela lógica capitalista, aqueles que são 'liberados' do processo de trabalho se tornam 
indigentes, 'mônadas monetárias sem dinheiro', na classificação de Robert Kurz (1996), eliminados do mundo do trabalho e possivelmente do mundo em si, como ponderou Gramsci (1980).

Apenas como outro exemplo, o cineasta Harun Farocki nos mostra, num filme de 1991,7 diversas experiências voltadas à medição da atividade cerebral. No que tal tecnologia está sendo usada nas filmagens que Farocki realiza? $\mathrm{Na}$ análise, através da atividade cerebral, de quais propagandas surtem maior efeito, de quais cenas publicitárias 'funcionam' melhor, de quais informes são vistos primeiro etc. Ou seja, o nível de eficácia alcançado por toda peça publicitária visa diretamente à produção futura de peças mais eficazes. Pesquisar, decifrar, controlar.

Não se trata de condenar determinada tecnologia ou estudo. Aliás, como o filósofo Günther Anders escreveu após a Segunda Guerra Mundial, tudo aquilo que podemos produzir não apenas não podemos não produzir, como não podemos não utilizar (Anders, 2003). O que é necessário urgente e permanentemente é a politização das novas tecnologias (Garcia dos Santos, 2003), que inclusive ficam 'velhas' numa velocidade impressionante. Nem bem discutimos os remédios, temos o advento de próteses, inclusive cerebrais, e já temos essa discussão posta mesmo no plano da genética, com promessas de 'melhoramento' da espécie.

\section{A fome e a vontade de comer}

O termo 'capital humano', hoje tão corrente e assimilado, teve um longo, embora rápido, percurso até os dias de hoje. Longo por ter causado verdadeira abjeção inicialmente e hoje ser foco das mais diversas políticas públicas, ou termo de propaganda de escolas de educação infantil; rápido pois a formulação do conceito, tal como conhecemos hoje, ocorre no início da década de 1960 por economistas ligados à Escola de Chicago.

O sociólogo Osvaldo López-Ruiz, num estudo que resgata o desenvolvimento desse conceito e de teorias do neoliberalismo, comenta:

A ciência econômica, nesse caso, não cria só uma teoria sobre a economia; cria um repertório de interpretação que nos permite pensar e pensar-nos de maneira tal que não nos resulte repulsiva a imagem do humano como riqueza - como o havia sido em tempos de J. S. Mill. A partir de seus postulados 'cientificamente verificáveis', o humano passa a ser entendido como uma forma de capital e, portanto, o 'capital humano' e tudo o que se faça para incrementá-lo é investido de um valor positivo: cada pessoa deve - porque é economicamente conveniente, mas também porque é 'moralmente bom' - aumentar suas habilidades (...) a partir de 'investimentos' constantes (López-Ruiz, 2007, p. 62, grifos nossos). 
Em 1979, 25 anos antes de López-Ruiz, Michel Foucault percebe que algo “está surgindo, que poderia ser, como quiserem, interessante ou inquietante" (Foucault, 2004, p. 233). Já que o capital humano só tem interesse para os economistas na medida em que se constitui de recursos raros utilizados para determinado fim, o filósofo afirma: “ora, é evidente que não temos que pagar pelo corpo que temos, ou que não temos que pagar para ter o equipamento genético que é nosso. Isso não custa nada. Sim, não custa nada - enfim, vai saber..." (Foucault, 2004, p. 233). E avaliando como o equipamento genético pode perfeitamente entrar nos cálculos econômicos: “o mecanismo de produção dos indivíduos, a produção dos filhos, pode desembocar em toda uma problemática econômica e social a partir da raridade dos bons equipamentos genéticos" (Foucault, 2004, p. 234). E lembremos que Foucault está fazendo tais considerações em sala de aula em 1979.

O que queremos destacar nesse ponto é a junção entre um pensamento social que legitima, estimula e exige o incremento ou desenvolvimento de capacidades que devem poder ser aproveitadas pelo mercado com um patamar tecnológico que permite 'incrementos' nunca vistos, a não ser na ficção científica. Os autores da Escola de Chicago pensaram na educação e condicionaram esta ao mercado, tratando-a como investimento. Foucault apenas levou a lógica às últimas consequências.

Nesse sentido, a redução da vida ao cálculo econômico adquire aqui a sua máxima expressão, ao mesmo tempo que se torna inteligível a matriz de uma forma inédita de eugenia, que já não passa mais por políticas de Estado, mas que se formula 'democraticamente' na incorporação das leis de mercado pelos indivíduos, incorporação que, acima de tudo, passa a reger o próprio processo de individuação. Com efeito, se mediante critérios definidos por regras do mercado passo a considerar minhas habilidades, capacidades e potencialidades como 'recursos' passíveis de valorização, isto é, como ativos de 'meu' capital humano, tendo 'naturalmente' a identificar e a buscar desenvolver, ou melhor, a selecionar tudo aquilo que deve me favorecer na competição. Mas ao fazer tal escolha, reitero a cada vez, em meu próprio processo de individuação, não o que penso escolher como melhor para mim, mas o que o capital programou para que eu escolhesse como melhor para ele. Assim, a seleção natural se transmuta em seleção naturalsocial, para usar o termo à la Donna Haraway, seleção que prenuncia e prepara o advento de uma 'segunda natureza' humana, como foi tão bem intuído por Gramsci (1980). Devemos, portanto, procurar a razão das novas práticas eugênicas emergentes, e suas condições de possibilidade, na própria lógica do capitalismo contemporâneo, e não nas fraquezas institucionais, na inconsciência ou inconsequência dos indivíduos, ou na incapacidade da 'bioética' de enfrentar os argumentos dos cientistas ou resistir às pressões das corporações da 'indústria da vida'. 
Enfim, não devemos condenar a pesquisa temendo que o homem tornese servo da máquina. O próprio termo 'servir' deveria ser combatido na medida em que oculta, em benefício da manutenção de certas relações de produção, o devir elementar envolvido na relação humano-máquina. Devemos estar atentos para que a obsessão explicativa, que encontramos não só no processo de substituição do humano pela máquina, mas também no de sua hibridização cada vez mais completa, não coloque impunemente o homem a serviço da máquina, mas sim contribua para o desenvolvimento das potencialidades positivas da própria relação humano-máquina.

\section{Notas}

1 Professor titular do Departamento de Sociologia do Instituto de Filosofia e Ciências Humanas (IFCH) da Universidade Estadual de Campinas (Unicamp) e coordenador do grupo Conhecimento, Tecnologia e Mercado (CTeMe). Doutor em Sciences de l'Information pela Universite de Paris VII - Universite Denis Diderot. Pós-doutorado pela École des Hautes Études en Sciences Sociales. <laymert@gmail.com>

Correspondência: Deptartamento de Sociologia, IFCH-Unicamp, Rua Cora Coralina, s/n, CEP 13081-970, Cidade Universitária, Campinas, SP, Brasil.

2 Doutorando em Ciências Sociais do Instituto de Filosofia e Ciências Humanas (IFCH) da Universidade Estadual de Campinas (Unicamp) e integrante do grupo Conhecimento, Tecnologia e Mercado (CTeMe). <rafaelcotuca@yahoo.com.br>

3 Professor adjunto do Departamento de Ciências Sociais (DCSo) do Centro de Educação e Ciências Humanas (CECH) da Universidade Federal de São Carlos (UFSCar) e integrante do grupo Conhecimento, Tecnologia e Mercado (CteMe). Doutor em Ciências Sociais pelo Programa de Doutorado em Ciências Sociais do Instituto de Filosofia e Ciências Humanas (IFCH) da Universidade Estadual de Campinas (Unicamp). < pedroferreira@ufscar.br>

4 Essa transição foi apontada por Hermann von Helmholtz ainda em 1854: “Hoje, já não tentamos construir máquinas que realizem as mil diferentes ações de um único homem; ao contrário, exigimos que a máquina realize uma única ação, mas substituindo mil homens" (apud Losano, 1992, p. 114, grifos no original).

5 Comunicação informal de pesquisadora do tema.

6 Sobre a concepção bergsoniana do cérebro como mediador sensório-motor, ver Bergson (1999).

7 Farocki, Harun. O que há? Alemanha Ocidental, 1991, 16 mm, cor, 60'. 


\section{Referências}

ANDERS, Günther. L'uomo è antiquato. 1. Considerazioni sull'anima nell'epoca della seconda rivoluzione industriale. Torino: Bollati Boringhieri, 2003.

BERCITO, Diogo. Impulso tecnológico deve ser analisado (entrevista com Ray Kurzweil). Folha de S.Paulo, 4 nov. 2007, caderno Negócios.

BERGSON, Henri. Matéria e memória: ensaio sobre a relação do corpo com o espírito. Tradução de Paulo Neves. São Paulo: Martins Fontes, 1999 [1897].

CLEMENTE, Ana T.; VEIGA, Aida. Receitas para a inteligência: a ciência descobre como alimentos, exercícios e remédios podem estimular o cérebro e melhorar seu desempenho. Época, n. 389, p. 77-78, 2005.

FOUCAULT, Michel. Naissance de la biopolitique. Paris: Galimard/Seuil, 2004 [1979]. (Coll. Hautes Études).

GARCIA DOS SANTOS, Laymert. Politizar as novas tecnologias: o impacto sócio-técnico da informação digital e genética. São Paulo: Editora 34, 2003.

GRAMSCI, Antonio. Americanismo e fordismo. In: Maquiavel, a política e o Estado moderno. Tradução de Luiz M. Gazzaneo. Rio de Janeiro: Civilização Brasileira, 1980 [1934]. p. 375-413.

KURZ, Robert. O colapso da modernização: da derrocada do socialismo de caserna à crise da economia mundial. Trad. Karen E. Barbosa. São Paulo: Paz e Terra, 1996 [1991].
LAURENCE, Jeremy. Cérebro turbinado: bioeticista pede liberação de drogas para 'doping mental', como a Ritalina, dizendo que elas são uma extensão natural da educação. Folha de S.Paulo, 21 jun. 2009, caderno Ciência.

LEBEDEV, Mikhail A. et al. Cortical ensemble adaptation to represent velocity of an artificial actuator controlled by a BrainMachine Interface. The Journal of Neuroscience, v. 25, n. 19, p. 4681-4693, 2005.

LOBO, Flavio. Brasileiro voador. Carta Capital, 18 jan. 2006, p. 8-16.

LÓPEZ-RUIZ, Osvaldo. Os executivos das transnacionais e o espírito do capitalismo: capital humano e empreendedorismo como valores sociais. Rio de Janeiro: Azougue, 2007.

LOSANO, Mario G. Histórias de autômatos: da Grécia Antiga à Belle Époque. Tradução de Bernardo Joffily. São Paulo: Companhia das Letras, 1992 [1990].

MANOVICH, Lev. The labor of perception. 1995. Disponível em: <www.manovich.net /TEXT/labor.html>. Acesso em: 31 out. 2010.

NICOLELIS, Miguel A. L. Actions from thoughts. Nature, n. 409, p. 403-407, 2001.

NICOLELIS, Miguel A. L.; CHAPIN, John K. Controlling robots with the mind. Scientific American, v. 287, n. 40, p. 46-53, 2002.

SANTOS, Wagner L. S. Telemarketing e produtividade. Cientefico, v. 7, n. 2, p. 156165, 2007. 